\title{
Impact of proximal radiopaque coronary bypass graft markers on postbypass surgery coronary angiography
}

\author{
Clarence Pingpoh, MD, ${ }^{\mathrm{a}, \mathrm{c}}$ Matthias Siepe, MD, ${ }^{\mathrm{a}, \mathrm{c}}$ Katharina Burger, Can. Med., ${ }^{\mathrm{a}, \mathrm{c}}$ Thomas Zietak, MD, \\ Christian M. Valina, MD, ${ }^{\mathrm{b}, \mathrm{c}}$ Miroslav Ferenc, MD,${ }^{\mathrm{b}, \mathrm{c}}$ Friedhelm Beyersdorf, MD, ${ }^{\mathrm{a}, \mathrm{c}}$ \\ Franz-Josef Neumann, MD, ${ }^{\mathrm{b}, \mathrm{c}}$ and Willibald Hochholzer, MD ${ }^{\mathrm{b}, \mathrm{c}}$
}

\begin{abstract}
Background: Implantation of radiopaque bypass graft markers during coronary artery bypass surgery $(\mathrm{CABG})$ has the potential of facilitating subsequent coronary angiography. This study sought to investigate the impact of proximal coronary bypass graft markers on angiographic outcomes during subsequent coronary angiography in a large cohort.
\end{abstract}

Methods and Results: Between 2005 and 2016, we enrolled 1378 patients (331 with and 1047 without bypass graft markers) with a history of CABG who underwent their first subsequent coronary angiography at our institution. Primary endpoints were radiation time and absolute amount of contrast media used. In unadjusted analyses, radiation time, duration of angiography, dose area product, and the amount of contrast agent were significantly lower in patients with proximal bypass graft markers $(P<.001)$. After full adjustment, proximal coronary bypass graft markers remained a significant predictor for less radiation time and a lower consumption of contrast agent but not for dose area product, which was mainly associated with body mass index and sex. Bypass graft markers were not associated with a lower graft patency.

Conclusions: Radiopaque coronary bypass graft markers can improve the detection of bypass grafts during subsequent coronary angiography and are associated with a lower radiation time and less consumption of contrast agent. Thus, this easy and cost-efficient technique might significantly reduce the risk of coronary angiography after CABG. (J Thorac Cardiovasc Surg 2018;155:1565-72)

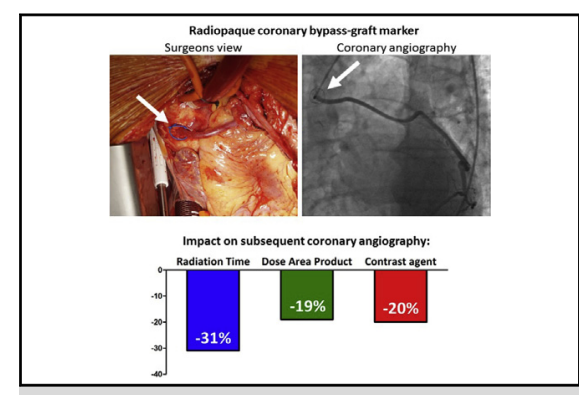

Proximal radiopaque coronary bypass graft marking. Arrows indicate location of radiopaque coronary bypass graft marker. Upper left panel, Implantation of marker during bypass surgery. Upper right panel, Angiographic view of this marked bypass graft.

\section{Central Message}

Radiopaque bypass graft markers improve detection of bypass grafts during subsequent coronary angiography and are associated with a lower radiation time and less consumption of contrast agent.

\section{Perspective}

Coronary angiography in patients with a history of CABG is more complex and challenging, given the additional vessels that have to be investigated and the high variability of the proximal bypass location. Radiopaque bypass graft markers are an easy and cost-efficient technique that can significantly reduce the radiation time and consumption of contrast agent during coronary angiography after CABG.

See Editorial Commentary page 1573.

\footnotetext{
From the Departments of ${ }^{\mathrm{a}}$ Cardiovascular Surgery and ${ }^{\mathrm{b}}$ Cardiology and Angiology II, University Heart Center Freiburg-Bad Krozingen, Bad Krozingen; and ${ }^{\mathrm{c}}$ Medical Faculty, Albert-Ludwigs-University Freiburg, Freiburg, Germany.

This trial was supported by the University Heart Center Freiburg-Bad Krozingen. Drs Pingpoh and Siepe contributed equally to this article.

Received for publication June 19, 2017; revisions received Dec 1, 2017; accepted for publication Dec 11, 2017; available ahead of print Jan 17, 2018.

Address for reprints: Clarence Pingpoh, MD, Department of Cardiovascular Surgery, University Heart Center Freiburg-Bad Krozingen, Suedring 15, Bad Krozingen 79189, Germany (E-mail: Clarence.Pingpoh@universitaets-herzzentrum.de). $0022-5223 / \$ 36.00$

Copyright (c) 2017 by The American Association for Thoracic Surgery https://doi.org/10.1016/j.jtcvs.2017.12.043
}

Saphenous vein grafting is still a very common coronary artery bypass grafting (CABG) technique, even in the era of multiple arterial grafting. ${ }^{1,2} \mathrm{~A}$ total of $10 \%$ to $20 \%$ of saphenous vein

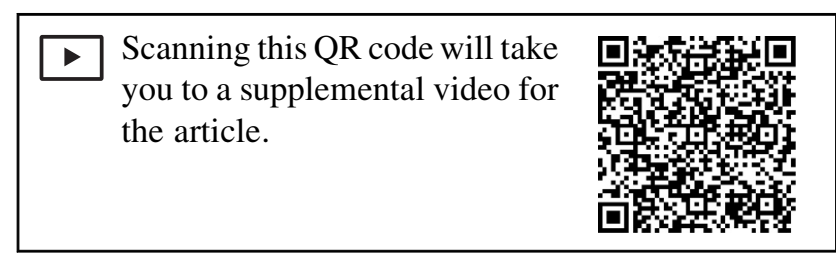




\section{Abbreviations and Acronyms}

$\mathrm{CABG}=$ coronary artery bypass grafting

CI-AKI $=$ contrast-induced acute kidney injury

grafts fail to work within the first year after coronary surgery. In the following 1 to 5 years, an additional $5 \%$ to $10 \%$ and from 6 to 10 years an additional $20 \%$ to $25 \%$ of the saphenous vein grafts degenerate. ${ }^{1-3}$ Thus, the graft patency at 10 years is only about $50 \%$, and a significant number of these patients need to undergo post-CABG coronary angiography due to angina or other signs of ischemia. ${ }^{1,2}$

Compared with patients without CABG, coronary angiography in patients with a history of CABG is often more complex and challenging, given the additional vessels that need to be investigated. ${ }^{3-6}$ It is important to know the type and number of bypass grafts before angiography to allow a focused examination. ${ }^{3-6}$ Without this information, there is the potential of greater contrast use associated with an increased risk of contrast-induced acute kidney injury (CI$\mathrm{AKI}$ ), greater radiation exposure to patients and angiographers, and a greater risk of vascular injury and bleeding, given additional catheter manipulations in the aorta. ${ }^{3-6}$ However, in clinical routine, data regarding bypass number and location are often not available or not sufficiently precise. The use of proximal radiopaque bypass graft markers during CABG might present an easy and durable solution to this problem. This technique has the potential of reducing the radiation time as well as the amount of contrast agent used by providing a visual guide to the origin of bypass grafts in the ascending aorta. ${ }^{6-10}$ Although this technique has been described in previous studies, it has not been evaluated in a large cohort so far. ${ }^{6-8}$ Thus, the present study sought to investigate whether proximal radiopaque coronary bypass graft markers have an impact on procedural characteristics of post-CABG coronary angiography and clinical outcome.

\section{METHODS}

\section{Study Population and Objectives}

This retrospective study analyzed patients with a history of CABG who underwent subsequent coronary angiography at the Department of Cardiology and Angiology II, University Heart Center Freiburg-Bad Krozingen, Bad Krozingen, Germany, from February 2005 until February 2016. The indication for coronary angiography was either acute coronary syndrome or suspected stable ischemia according to positive stress testing or typical clinical symptoms. There was no routine angiographic follow-up. The study was approved by the ethics committee of the University of Freiburg (Germany) and has been registered at the German Clinical Trial Register (drks.de, identifier: DRKS00010298).

The objective of this study was to evaluate the impact of proximal coronary bypass graft markers on angiographic and clinical outcomes during and after subsequent coronary angiography. The primary hypothesis was that radiopaque markers of the proximal bypass graft would be associated with a reduced radiation time and contrast medium consumption.
Key inclusion criteria were history of CABG and subsequent first coronary angiography from February 2005 until February 2016 at our institution. Patients with available results (imaging film) of a previous coronary angiography after $\mathrm{CABG}$ or known occlusion of all proximal bypass grafts were excluded from this analysis because these data would most likely have impacted the angiographic endpoints. Further exclusion criteria were missing film of the present coronary angiography, which was used as proof of proximal coronary bypass graft markers, missing records of the angiographic endpoints, or if the patient did not receive any proximal bypass graft anastomosis (eg, only internal mammary artery grafts with origin from the subclavian artery).

Patients were stratified into 2 cohorts: (1) those with marked proximal bypass grafts (clinical routine in the University Heart Center in Bad Krozingen for the last decades) and (2) those without any proximal bypass graft markings (routine in most other centers). In the present analysis, all patients with bypass markers received their surgery at the University Heart Center in Bad Krozingen, and almost all patients without markers were operated at multiple different hospitals.

\section{Proximal Coronary Bypass Graft Marking Technique}

After routine $\mathrm{CABG}$ with the use of vein or arterial grafts, the aortic connection of the graft was marked with a radiopaque marker (Central Figure). At our institution, we use the marking strip of a sterile swap to circumference the proximal anastomosis, which is knotted loosely with suture material. Whenever 2 proximal anastomoses are performed, the radiopaque marker is positioned in a figure-of-eight style around the 2 anastomoses (Video 1). Currently, there are no commercially produced graft markers available in Europe that are approved for this use.

\section{Clinical Endpoints}

The primary endpoints were the radiation time of the coronary angiography and the absolute amount of iodinated contrast media used. The key secondary end points included radiation exposure of the diagnostic procedure (dose area product) and laboratory parameters if available.

\section{Statistics}

Discrete variables are reported as counts (percentages) and continuous variables as median and quartiles. For discrete variables, we tested differences between groups with the $\chi^{2}$ test or Fisher exact test when expected cell sizes were less than 5 . The Mann-Whitney $U$ test was used for comparison of non-Gaussian continuous variables. In the 2 -sided test, a $P$ value $<.05$ was regarded as significant. Given the 2 primary endpoints, $P<.25$ was regarded as significant in these analyses.

Linear or binary regression models were used to calculate regression coefficients or odds ratios with associated $95 \%$ confidence intervals.

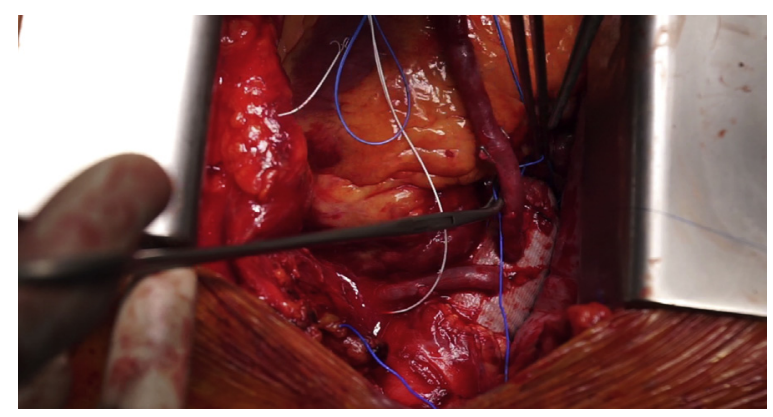

VIDEO 1. Placement of a radiopaque bypass marker on 2 venous proximal bypass grafts. Video available at: http://www.jtcvsonline.org/article/ S0022-5223(17)32889-1/fulltext. 
Statistical analyses were run with IBM SPSS Statistics, version 22 (IBM Corp, Armonk, NY).

\section{RESULTS}

\section{Study Population}

From February 2005 until February 2015, 1859 patients underwent their first coronary angiography after CABG. Altogether, 481 patients were excluded from this analysis because they did not receive any proximal graft connection to the aorta (eg, only internal mammary artery grafts) or they had an already known occlusion of all bypass grafts. From the remaining 1378 patients, 331 had received proximal radiopaque coronary bypass graft markers and 1047 had no markers. Baseline characteristics of these 2 cohorts are shown in Table 1.
Patients with a proximal bypass graft marker were significantly older, showed a trend toward less cardiovascular risk factors, had more frequently a cardiac troponin above reference limit and a reduced left ventricular function on admission, were less often in New York Heart Association class III or IV, and had received more bypass segments during their index bypass surgery.

\section{Angiographic Characteristics}

Table 2 shows the angiographic characteristics of both cohorts. The first coronary angiography after CABG was performed at medium 115 months thereafter (interquartile range 67-169 months) with no significant differences between cohorts. The majority of patients were diagnosed

TABLE 1. Baseline characteristics

\begin{tabular}{|c|c|c|c|}
\hline & \multicolumn{2}{|c|}{ Proximal radiopaque coronary vein graft marking } & \multirow[b]{3}{*}{$P$ value } \\
\hline & Yes & No & \\
\hline & $\mathbf{n}=\mathbf{3 3 1}$ & $\mathrm{n}=1047$ & \\
\hline Age, y & $73(68-78)$ & $71(65-77)$ & .001 \\
\hline Male & $286(86.4 \%)$ & $871(83.2 \%)$ & .17 \\
\hline Active smoker & $17(5.1 \%)$ & $83(7.9 \%)$ & .09 \\
\hline Arterial hypertension & $290(87.6 \%)$ & $951(90.8 \%)$ & .09 \\
\hline Hypercholesterolemia & $274(82.8 \%)$ & $932(89.0 \%)$ & .003 \\
\hline Diabetes mellitus & $90(27.2 \%)$ & $367(35.1 \%)$ & .008 \\
\hline Body mass index, $\mathrm{kg} / \mathrm{m}^{2}$ & $27.0(24.6-29.4)$ & $27.4(24.8-30.1)$ & .18 \\
\hline Hemoglobin, g/dL & $14.0(12.8-15.1)$ & $14.0(12.8-14.9)$ & .48 \\
\hline Glomerular filtration rate, $\mathrm{mL} / \mathrm{min}$ & $66(49-84)$ & $68(52-87)$ & .18 \\
\hline C-reactive protein, $\mathrm{mg} / \mathrm{L}$ & $3(2-6)$ & $3(2-6)$ & .15 \\
\hline Cardiac troponin above reference limit & $135(40.8 \%)$ & $357(34.1 \%)$ & .03 \\
\hline \multicolumn{4}{|l|}{ Medication on admission } \\
\hline Aspirin & $229(69.2 \%)$ & $791(75.5 \%)$ & .02 \\
\hline Oral anticoagulation & $63(19.0 \%)$ & $158(15.1 \%)$ & .09 \\
\hline$\beta$-Blockers & $259(78.2 \%)$ & $809(77.3 \%)$ & .71 \\
\hline ACE inhibitors & $181(54.7 \%)$ & $541(51.7 \%)$ & .34 \\
\hline Statins & $251(75.8 \%)$ & $797(76.1 \%)$ & .91 \\
\hline Previous balloon angioplasty & $3(0.9 \%)$ & $1(0.1 \%)$ & .02 \\
\hline Previous myocardial infarction & $147(44.4 \%)$ & $475(45.4 \%)$ & .76 \\
\hline Left ventricular ejection fraction & & & .003 \\
\hline$\geq 55 \%$ & $163(49.2 \%)$ & $590(56.4 \%)$ & \\
\hline $40 \%-54 \%$ & $75(22.7 \%)$ & $251(24.0 \%)$ & \\
\hline $30 \%-39 \%$ & $63(19.0 \%)$ & $118(11.3 \%)$ & \\
\hline$<30 \%$ & $30(9.1 \%)$ & $88(8.4 \%)$ & \\
\hline CCS angina class III or IV & $143(43.2 \%)$ & $250(43.0 \%)$ & .21 \\
\hline NYHA class III or IV & $91(27.4 \%)$ & $340(32.5 \%)$ & .001 \\
\hline Number of bypass segments & & & $<.001$ \\
\hline$<3$ & $85(25.7 \%)$ & $284(27.1 \%)$ & \\
\hline $3-4$ & $186(56.2 \%)$ & $687(65.6 \%)$ & \\
\hline$>4$ & $60(18.1 \%)$ & $76(7.3 \%)$ & \\
\hline
\end{tabular}

Data are expressed as median and quartiles or number of patients (percentage). $P$ by Mann-Whitney $U$ or $\chi^{2}$ test. $A C E$, Angiotensin-converting enzyme; $C C S$, Canadian Cardiovascular Society; NYHA, New York Heart Association. 
TABLE 2. Angiographic characteristics

\begin{tabular}{|c|c|c|c|}
\hline & \multicolumn{2}{|c|}{ Proximal radiopaque coronary vein graft marking } & \multirow[b]{3}{*}{$P$ value } \\
\hline & Yes & No & \\
\hline & $\mathbf{n}=\mathbf{3 3 1}$ & $\mathbf{n}=\mathbf{1 0 4 7}$ & \\
\hline Year of bypass surgery & $1999(1993-2005)$ & $2000(1996-2004)$ & .14 \\
\hline Months since bypass surgery & $112(41-208)$ & $115(67-169)$ & .70 \\
\hline Three-vessel disease & $290(87.9 \%)$ & $898(86.7 \%)$ & .79 \\
\hline Mean max. stenosis of vein graft, $\%$ & $38(0-100)$ & $62(0-100)$ & .12 \\
\hline Any vein graft with stenosis $\geq 50 \%, \%$ & $160(48.3 \%)$ & $547(52.2 \%)$ & .22 \\
\hline Total occlusion of any vein graft, $\%$ & $126(38.1 \%)$ & $419(40.0 \%)$ & .53 \\
\hline Acute coronary syndrome & $83(25.1 \%)$ & $303(28.9 \%)$ & .17 \\
\hline Coronary stent implantation & $168(50.8 \%)$ & $634(60.6 \%)$ & .002 \\
\hline Duration of angiography, min & $48(31-76)$ & $60(38-97)$ & $<.001$ \\
\hline Radiation time, min & $9(5-20)$ & $13(7-26)$ & $<.001$ \\
\hline Dose area product, cGy $\times \mathrm{cm}^{2}$ & $4779(2789-8174)$ & $5900(3501-10,102)$ & $<.001$ \\
\hline Contrast agent used, $\mathrm{mL}$ & $160(110-230)$ & $200(120-300)$ & $<.001$ \\
\hline
\end{tabular}

Data are expressed as median and quartiles or number of patients (percentage). $P$ by Mann-Whitney $U$ or $\chi^{2}$ test.

with 3-vessel disease. A total occlusion of at least 1 bypass graft was found in $\sim 40 \%$ of patients without differences between the groups. A percutaneous coronary or bypass intervention with stent implantation was more frequently needed in patients without proximal coronary bypass graft markers.

\section{Bypass Graft Patency With and Without Markers}

Proximal coronary vein graft marking was associated with similar or greater patency rates as compared with nonbypass marking in almost all subgroups (Table 3). This finding was most prominent with most recent bypass surgery and greater numbers of bypass segments. In an adjusted binary logistic regression model for prediction of a stenosis $>50 \%$ in any bypass graft including all variables from Table 1 and time since bypass surgery, a proximal bypass marker was the only variable significantly associated with lower risk (odds ratio, $0.72 ; 95 \%$ confidence interval, $0.55-0.95 ; P=.02$ ). Time since bypass surgery and number of bypass segments were the only significant predictors of bypass graft stenosis $(P<.001)$.

The duration of the coronary angiography, radiation time, the dose area products, as well as the amount of contrast agent used were significantly reduced in patients with proximal bypass graft markers (Table 2, Figure 1). This trend persisted when analyzing patients undergoing only diagnostic coronary angiography and patients undergoing coronary interventions separately (Figure 2).

\section{Adjusted Analyses}

After full adjustment in a linear regression model, proximal coronary bypass graft markers remained a significant predictor for less radiation time and a lower consumption of contrast agent (Table 4). Regarding dose area product, a proximal bypass graft marker was only associated with a trend toward lower results. Body mass index and sex were the main predictors of a greater dose area product, together with total occlusion of a bypass and coronary stent implantation. The latter 2 parameters were, as expected, also significantly associated with a greater radiation time and a greater consumption of contrast agent. Further analyses demonstrated a consistent effect of proximal bypass graft markers on angiographic outcomes across various subgroups (Figure 2). There was a nonsignificant trend for all 3 analyzed angiographic outcomes toward a greater effect with increasing number of bypass segments. The expertise of the interventionalist did not interact with the effect of bypass marking.

\section{DISCUSSION}

Coronary angiography after CABG is an important diagnostic tool for evaluating bypass graft patency in patients presenting with angina or ischemia. ${ }^{1-4}$ Furthermore, coronary interventions in diseased bypass grafts are common practice for the treatment of graft atherosclerosis, especially of venous grafts. ${ }^{9}$ The lack of knowledge pertaining to the type and numbers of bypass grafts before catheterization makes coronary angiography in patients with coronary artery bypass grafts often more complex. ${ }^{3-6}$ The risks associated with such an invasive procedure are obvious, and over the past 20 years, the number and complexity of interventional cardiology procedures has significantly increased. ${ }^{11}$ Over the last decades, surgeons of different departments worldwide have used rings to mark the ostia of the vein grafts to facilitate identification of graft ostia during subsequent coronary angiography. ${ }^{5-9}$ In recent years, this practice has been abandoned because of concerns regarding a negative 
TABLE 3. Patency of bypass graft connected to the ascending aorta in selected subgroups

\begin{tabular}{|c|c|c|c|}
\hline & \multicolumn{2}{|c|}{$\begin{array}{l}\text { Proximal radiopaque } \\
\text { coronary vein } \\
\text { graft marking }\end{array}$} & \multirow[b]{2}{*}{$P$ value } \\
\hline & Yes $(\%)$ & No $(\%)$ & \\
\hline \multicolumn{4}{|l|}{ Age, y } \\
\hline$\leq 65$ & $39(61.9)$ & $128(48.9)$ & .07 \\
\hline $65-75$ & $69(50.0)$ & $216(45.9)$ & .44 \\
\hline$>75$ & $63(48.5)$ & $156(49.7)$ & .84 \\
\hline \multicolumn{4}{|l|}{ Sex } \\
\hline Male & $142(49.7)$ & $468(53.7)$ & .34 \\
\hline Female & $29(64.4)$ & $97(55.1)$ & .31 \\
\hline \multicolumn{4}{|l|}{ Active smoker } \\
\hline Yes & $11(64.7)$ & $41(49.4)$ & .30 \\
\hline No & $160(51.0)$ & 459 (47.6) & .33 \\
\hline \multicolumn{4}{|c|}{ Diabetes mellitus } \\
\hline Yes & $41(45.6)$ & $165(45.0)$ & 1.00 \\
\hline No & $130(53.9)$ & $335(49.3)$ & .23 \\
\hline \multicolumn{4}{|c|}{ Acute coronary syndrome } \\
\hline Yes & $32(38.6)$ & $100(33.0)$ & .36 \\
\hline No & $139(56.0)$ & $400(53.8)$ & .56 \\
\hline \multicolumn{4}{|c|}{ Year of bypass surgery } \\
\hline$\leq 1995$ & $26(24.3)$ & $70(28.7)$ & .44 \\
\hline $1996-2005$ & $87(57.6)$ & $327(52.2)$ & .14 \\
\hline$>2005$ & $58(79.5)$ & $103(58.2)$ & .001 \\
\hline \multicolumn{4}{|c|}{ Years since bypass surgery } \\
\hline$\leq 5 \mathrm{y}$ & $81(77.1)$ & $142(61.7)$ & .006 \\
\hline$>5-10 y$ & $37(55.2)$ & $181(57.8)$ & .78 \\
\hline$>10 y$ & $53(33.3)$ & $177(35.1)$ & .70 \\
\hline \multicolumn{4}{|c|}{ Number of bypass segments } \\
\hline$<3$ & $49(57.6)$ & 209 (73.6) & .007 \\
\hline $3-4$ & $92(49.5)$ & 279 (40.6) & .04 \\
\hline$>4$ & $30(50.0)$ & $12(15.8)$ & $<.001$ \\
\hline
\end{tabular}

Bypass graft patency defined as no stenosis $\geq 50 \%$ in any bypass graft connected to the ascending aorta. Data are expressed as number of patients (percentage). $P$ by $\chi^{2}$ test.

impact on graft patency. ${ }^{6-9}$ However, there are no published data supporting these concerns so far. There are also no data from large cohorts, proving that this simple and quick addition to the index procedure, which is usually done during the reperfusion phase after on-pump CABG, can provide the assumed protective effect for patients.

The results of the present study demonstrate for the first time the clinical importance of radiopaque bypass graft markers in a large cohort of patients with a history of CABG undergoing coronary angiography. Key findings of this analysis are that this technique is associated with a lower burden on the patient during cardiac catheterization as shown by the significantly lower absolute amount of contrast media used as well as the shorter radiation time. Adjusted analyses also did demonstrate that there was no greater incidence of graft failure but even a significant trend toward an improved graft patency. These results imply that

\section{Radiation time}

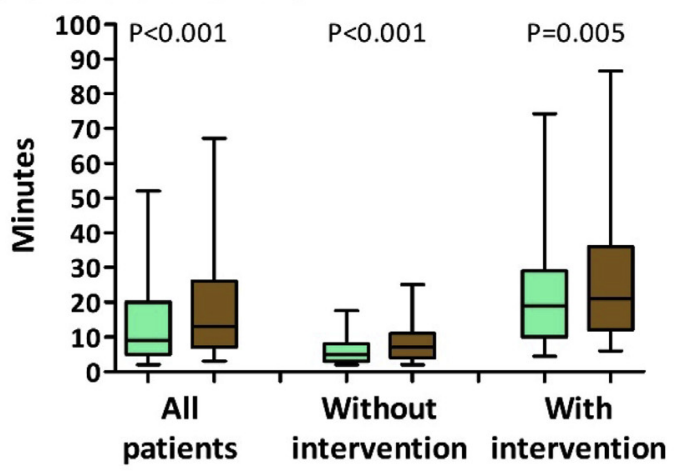

\section{Dose area product}

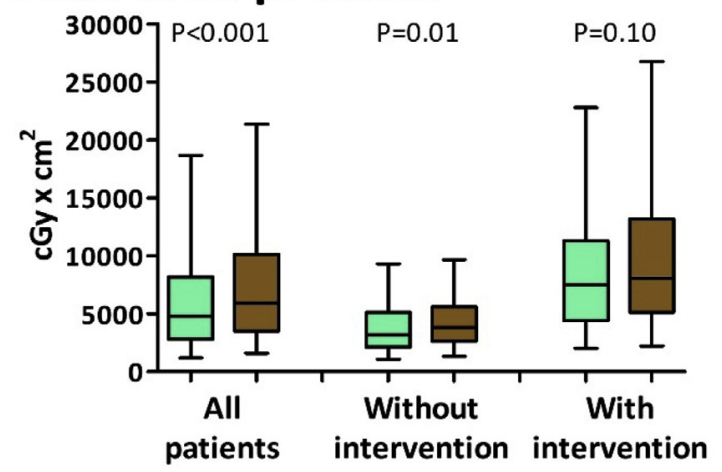

\section{Contrast agent}

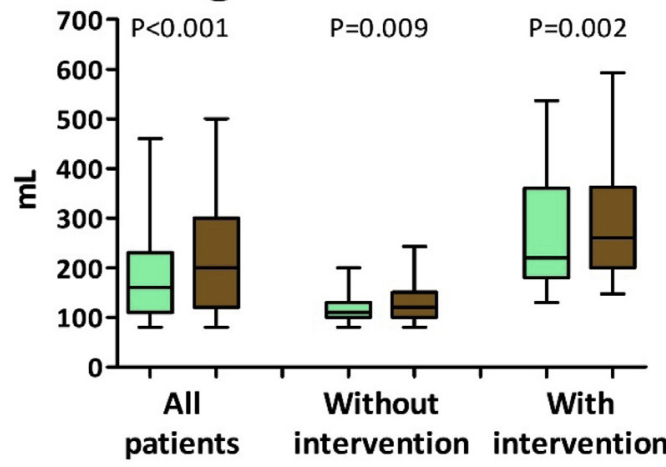

\section{Proximal radiopaque vein-graft marking: $\square$ Yes $\square$ No}

FIGURE 1. Angiographic parameters stratified according to coronary intervention status. Whiskers indicate $95 \%$ percentile. $P$ by MannWhitney $U$ test.

this easy and cost-efficient technique might have the potential to significantly reduce major adverse events associated with coronary angiography after CABG such contrastinduced renal injury or major vascular complications.

The negative effects of $\mathrm{X}$-ray radiation on patients and medical staff are well known. ${ }^{12-14}$ The clinical benefit of limiting X-ray radiation exposure has been demonstrated in several studies. ${ }^{15,16}$ Thus, radiation safety is a key item 

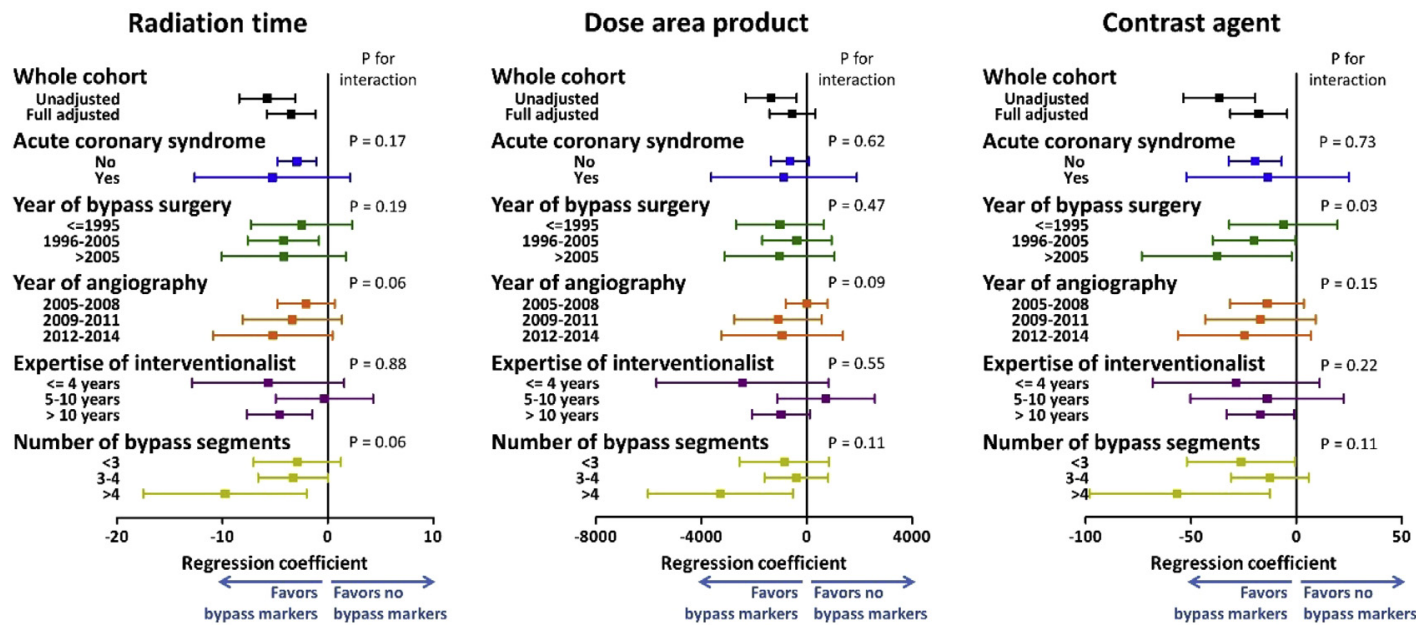

FIGURE 2. Impact of bypass graft markers on angiographic parameters in selected subgroups. Data presented as regression coefficients with $95 \%$ confidence intervals. $P$ by linear regression analyses. Full adjustment in the whole cohort as demonstrated in Table 4 . Subgroup analyses adjusted for key baseline and angiographic variables (age, hypercholesterolemia, diabetes, glomerular filtration rate, left ventricular ejection fraction, New York Heart Association class, coronary stent implantation). The interaction terms represent the interaction of the specific subgroup with the impact of bypass marking on the specific endpoint.

in medical imaging, and the current literature recommends a reduction of radiation exposure as much as possible. ${ }^{15-17}$ The routine means of protection, such as a lead apron, leaded glass goggles, and technical improvements of radiation equipment, can only provide partial protection for staff and patients. ${ }^{18,19}$ One of the key items to achieve a lower radiation exposure is reducing the procedural time. Therefore, the use of bypass graft markers might be an important supporting item in this setting as demonstrated by our study.

Nephrotoxicity due to iodinated contrast products has been intensively investigated over the past decades as well as prophylactic approaches for the prevention of nephrotoxicity. ${ }^{20-25}$ However, the most promising approach appears to be the reduction of the amount of contrast media being used. Bypass graft markers are associated with a lower consumption of contrast agent during coronary angiography as shown by our analysis and might therefore reduce the incidence of CI-AKI.

Already 2 decades ago, several small studies demonstrated the potential benefits of the use of bypass graft markers for subsequent coronary angiography. Peterson and colleagues ${ }^{5}$ could demonstrate in 76 patients with bypass markers undergoing cardiac catheterization post-CABG that bypass graft markers were associated with a reduced radiation exposure of both the patient and the physician as well as the amount of iodinated contrast media used. Eisenhauer and colleagues ${ }^{6}$ reported a significant reduction of radiation time, contrast volume, and numbers of angiographic catheters used in 100 patients with bypass markers. This trend was also confirmed in the smaller cohort of Peterson and colleagues, who showed that bypass graft markers improved the efficiency of post-CABG catheterizations by decreasing the exposure of patients and physicians to radiation as well as the amount of contrast media used. The results of the present study extend these previous findings by providing for the first time the results of a large cohort and by demonstrating that the impact of this simple technique on post-CABG coronary angiography still prevails despite the significant improvements in catheterization techniques, the skills of the cardiovascular interventionalist, and technical advances for reduction of radiation exposure.

\section{Limitations}

This analysis is retrospective with all adherent limitations. There was no dedicated screening for CI-AKI. Even if a second result for creatinine was documented within the first 24 hours after percutaneous coronary intervention in some patients, further controls beyond 24 hours were only available in very few patients. Thus, this analysis cannot prove whether the findings on angiographic characteristics impacted on the incidence of CI-AKI. A previous study has demonstrated a greater incidence of perioperative myocardial infarction with bypass marking. ${ }^{9}$ The present study cannot provide data on this item. However, the data on long-term patency of marked bypasses indicate that marking appears not to have any negative impact on this most critical safety parameter. Further limitations are missing data on the postoperative course and hard clinical outcomes as well as the clinical outcome of patients without subsequent coronary angiography. 
TABLE 4. Adjusted linear regression models

\begin{tabular}{|c|c|c|c|c|c|c|}
\hline & \multicolumn{2}{|l|}{ Radiation time } & \multicolumn{2}{|l|}{ Dose area product } & \multicolumn{2}{|l|}{ Contrast agent } \\
\hline & $\begin{array}{l}\text { Reg. } \\
\text { coef. }\end{array}$ & $P$ value & $\begin{array}{l}\text { Reg. } \\
\text { coef. }\end{array}$ & $P$ value & $\begin{array}{l}\text { Reg. } \\
\text { coef. }\end{array}$ & $P$ value \\
\hline Prox. bypass marker used & $-3.46(-5.78$ to -1.13$)$ & .004 & $-540.76(-1412.92$ to 331.41$)$ & .22 & $-17.90(-31.39$ to -4.41$)$ & .009 \\
\hline Age & $-0.04(-0.18$ to 0.10$)$ & .55 & $14.41(-38.57$ to 67.39$)$ & .59 & $-0.16(-0.98$ to 0.66$)$ & .70 \\
\hline Male & $0.56(-2.25$ to 3.36$)$ & .70 & $-1680.25(-2732.41$ to -628.08$)$ & .002 & $-2.76(-19.03$ to 13.51$)$ & .74 \\
\hline Active smoker & $1.06(-2.81$ to 4.93$)$ & .59 & $22.65(-1429.80$ to 1475.10$)$ & .98 & $-12.07(-34.53$ to 10.40$)$ & .29 \\
\hline Arterial hypertension & $-0.93(-4.34$ to 2.49$)$ & .59 & $-236.72(-1517.45$ to 1044.0$)$ & .72 & $2.31(-17.50$ to 22.11$)$ & .82 \\
\hline Hypercholesterolemia & $-2.57(-5.64$ to 0.5$)$ & .10 & $-477.69(-1628.85$ to 673.48$)$ & .42 & $-12.02(-29.82$ to 5.79$)$ & .19 \\
\hline Diabetes mellitus & 0.85 (-1.35 to 3.04$)$ & .45 & 258.48 ( -564.50 to 1081.46$)$ & .54 & $10.68(-2.04$ to 23.41$)$ & .10 \\
\hline Body mass index & $0.12(-0.14$ to 0.38$)$ & .36 & 343.79 (246.26 to 441.32$)$ & $<.001$ & $1.07(-0.44$ to 2.58$)$ & .16 \\
\hline Hemoglobin & $-0.15(-0.80$ to 0.50$)$ & .66 & $-147.91(-391.83$ to 96.01$)$ & .23 & $1.95(-1.83$ to 5.72$)$ & .31 \\
\hline Glomerular filtration rate & $0.02(-0.03$ to 0.06$)$ & .50 & $15.39(-1.12$ to 31.89$)$ & .07 & $0.16(-0.10$ to 0.41$)$ & .23 \\
\hline C-reactive protein & $-0.24(-0.66$ to 0.18$)$ & .26 & $-67.85(-226.35$ to 90.66$)$ & .40 & $-1.95(-4.40$ to 0.50$)$ & .12 \\
\hline Cardiac troponin above ref. limit & 0.31 ( -1.99 to 2.61$)$ & .79 & 579.16 ( -284.07 to 1442.39$)$ & .19 & $1.37(-11.98$ to 14.72$)$ & .84 \\
\hline Aspirin & $-1.24(-3.84$ to 1.37$)$ & .35 & $-538.07(-1514.08$ to 437.95$)$ & .28 & $-3.21(-18.3$ to 11.89$)$ & .68 \\
\hline Oral anticoagulation & $0.66(-2.35$ to 3.66$)$ & .67 & $247.96(-877.66$ to 1373.59$)$ & .67 & $7.95(-9.46$ to 25.36$)$ & .37 \\
\hline$\beta$-Blockers & $-1.94(-4.40$ to 0.52$)$ & .12 & $-625.81(-1547.42$ to 295.79$)$ & .18 & $-6.54(-20.79$ to 7.72$)$ & .37 \\
\hline ACE inhibitors & $1.17(-0.86$ to 3.2$)$ & .26 & $48.09(-713.25$ to 809.43$)$ & .90 & $6.71(-5.06$ to 18.49$)$ & .26 \\
\hline Statins & $2.17(-0.30$ to 4.64$)$ & .09 & $298.62(-628.74$ to 1225.98$)$ & .53 & $11.52(-2.82$ to 25.86$)$ & .12 \\
\hline Previous balloon angioplasty & $-15.87(-33.9$ to 2.16$)$ & .08 & $-4587.58(-11,349.6$ to 2174.46$)$ & .18 & $-90.30(-194.88$ to 14.28$)$ & .09 \\
\hline Previous myocardial infarction & $0.29(-1.75$ to 2.34$)$ & .78 & 242.80 ( -524.41 to 1010.02$)$ & .53 & $12.12(0.25-23.98)$ & .05 \\
\hline Left ventricular ejection fraction & $-0.75(-1.84$ to 0.33$)$ & .17 & $-127.63(-534.25$ to 278.99$)$ & .54 & $-7.13(-13.42$ to -0.84$)$ & .03 \\
\hline CCS angina class III or IV & $-0.09(-0.48$ to 0.30$)$ & .65 & $-13.43(-160.19$ to 133.33$)$ & .86 & $-0.38(-2.65$ to 1.89$)$ & .74 \\
\hline NYHA class III or IV & $0.14(-0.25$ to 0.53$)$ & .47 & $-16.55(-163.08$ to 129.97$)$ & .82 & $-0.57(-2.83$ to 1.70$)$ & .62 \\
\hline Number of bypass segments & $1.63(-0.22$ to 3.49$)$ & .08 & $482.02(-215.08$ to 1179.11$)$ & .18 & 9.11 ( -1.67 to 19.89$)$ & .10 \\
\hline Year of bypass surgery & $0.16(-0.05$ to 0.37$)$ & .13 & $165.96(88.20-243.72)$ & $<.001$ & $1.28(0.08-2.48)$ & .04 \\
\hline Months since bypass surgery & $0.01(0-0.02)$ & .02 & $6.82(2.97-10.66)$ & .001 & $0.05(-0.01$ to 0.11$)$ & .09 \\
\hline Three-vessel disease & $0.10(-2.14$ to 2.34$)$ & .93 & $319.87(-520.45$ to 1160.19$)$ & .46 & $6.33(-6.66$ to 19.33$)$ & .34 \\
\hline Total occlusion of any vein graft & $5.37(3.24-7.50)$ & $<.001$ & $1558.72(759.35-2358.09)$ & $<.001$ & $26.14(13.78-38.50)$ & $<.001$ \\
\hline Acute coronary syndrome & $11.40(8.92-13.88)$ & $<.001$ & $3339.47(2409.68-4269.26)$ & $<.001$ & $54.85(40.47-69.23)$ & $<.001$ \\
\hline Coronary stent implantation & $13.05(10.77-15.33)$ & $<.001$ & $4120.48(3265.15-4975.82)$ & $<.001$ & $132.69(119.46-145.92)$ & $<.001$ \\
\hline
\end{tabular}

$C I$, Confidence interval; $A C E$, angiotensin-converting enzyme; CCS, Canadian Cardiovascular Society; NYHA, New York Heart Association.

\section{CONCLUSIONS}

Radiopaque bypass graft markers can improve the detection of bypass grafts during subsequent coronary angiography and are associated with a lower radiation time and less consumption of contrast agent. Even if this study could not prove an impact on clinical outcome, this easy and cost-efficient technique appears to be safe and might significantly reduce the risk of coronary angiography after $\mathrm{CABG}$.

\section{Conflict of Interest Statement}

Dr Hochholzer reports receiving consulting and lecture fees from AstraZeneca, Boehringer Ingelheim, Daiichi Sankyo, and The Medicines Company. All other authors have nothing to disclose with regard to commercial support.

\section{References}

1. Sabik JF. Understanding saphenous vein graft patency. Circulation. 2011;124 273-5.

2. Favaloro RG, Effler DB, Groves LK, Sheldon WC, Riahi M. Direct myocardial revascularization with saphenous vein autograft. Clinical experience in 100 cases. Dis Chest. 1969;56:279-83.

3. Moshkovitz Y, Raanani E. The art of saphenous vein grafting and patency maintenance. J Thorac Cardiovasc Surg. 2016;151:300-2.

4. Movahed MR, Stinis CT. A new proposed simplified classification of coronary artery bifurcation lesions and bifurcation interventional techniques. J Invasive Cardiol. 2006;18:199-204.

5. Peterson RL, McKenzie RC, Ludbrook AP, Sundt TM III, Eichling JO, Schardan-Watson G, et al. Value of saphenous vein graft markers during 
subsequent diagnostic cardiac catheterization. Ann Thorac Surg. 1999;68: 2263-6.

6. Eisenhauer MD, Collier E III, Eisenhauer TL, Cambier PA. Beneficial impact of aorto-coronary graft markers on post-operative angiography. Cathet Cardiovasc Diagn. 1997;40:249-53.

7. Eisenhauer MD, Malik JA, Coyle LC, Arendt MA. Impact of aorto-coronary graft markers on subsequent graft patency: a retrospective review (review). Cathet Cardiovasc Diagn. 1997;42:259-61.

8. Nunes CF, Bolooki H. Aorta-coronary graft anastomosis marker: more than 30 years of experience. J Thorac Cardiovasc Surg. 2005;130:583-4.

9. Olenchock AS Jr, Karmpaliotis D, Gibson WJ, Murphy SA, Southard MC, Ciaglo L, et al. Impact of saphenous vein graft radiographic markers on clinical events and angiographic parameters. Ann of Thorac Surg. 2008; 85:520-4.

10. Çıkırıkçığlu M, Özbay G, Duran E. Proximal anastomotic marker use in coronary artery bypass operations. Anatol J Cardiol. 2002;2:138-41.

11. Plessis J, Fresse WK, Cahouch Z, Manigold T, Letocart V, Le Gloan L, et al Value of image fusion in coronary angiography for the detection of coronary artery bypass grafts. J Am Heart Assoc. 2016;5:e002233.

12. Wagner LK, Eifel PJ, Geise RA. Potential biological effects following high X-ray dose interventional procedures. J Vasc Interv Radiol. 1994;5:71-84.

13. Balter S, Hopewell JW, Miller DL, Wagner LK, Zelefsky MJ. Fluoroscopically guided interventional procedures: a review of radiation effects on patients' skin and hair. Radiology. 2010;254:326-41.

14. Delichas M, Psarrakos K, Molyvda-Athanassopoulou E, Giannoglou G, Sioundas A, Hatziioannou K, et al. Radiation exposure to cardiologists performing interventional cardiology procedures. Eur J Radiol. 2003;48: 268-73.

15. Georges JL, Belle L, Etard C, Azowa JB, Albert F, Pansieri M, et al. The Ray'act2 Investigators. Radiation doses to patients in interventional coronary procedures - estimation of updated national reference levels by dose audit. Radiat Prot Dosimetry. 2017;175:17-25.
16. Kuon E, Glaser C, Dahm JB. Effective techniques for reduction of radiation dosage to patients undergoing invasive cardiac procedures. Br J Radiol. 2003; 76:406-13.

17. Cousins C, Miller DL, Bernardi G, Rehani MM, Schofield P, Vañó E, et al. International Commission on Radiological Protection. ICRP Publication 120: radiological protection in cardiology. Ann ICRP. 2013;42:1-125.

18. Goldstein JA, Balter S, Cowley M, Hodgson J, Klein LW, Interventional Committee of the Society of Cardiovascular Interventions. Occupational hazards of interventional cardiologists: prevalence of orthopedic health problems in contemporary practice. Catheter Cardiovasc Interv. 2004;63:407-11.

19. Ross AM, Segal J, Borenstein D, Jenkins E, Cho S. Prevalence of spinal disc disease among interventional cardiologists. Am J Cardiol. 1997;79:68-70.

20. Chalikias G, Drosos I, Tziakas DN. Contrast-induced acute kidney injury: an update. Cardiovasc Drugs Ther. 2016;30:215-28.

21. Wi J, Ko YG, Kim JS, Kim BK, Choi D, Ha JW, et al. Impact of contrast-induced acute kidney injury with transient or persistent renal dysfunction on long-term outcomes of patients with acute myocardial infarction undergoing percutaneous coronary intervention. Heart. 2011;97:1753-7.

22. Weisbord SD. Iodinated contrast media and the kidney. Rev Cardiovasc Med. 2008;9:14-23.

23. Chang TI, Leong TK, Boothroyd DB, Hlatky MA, Go AS. Acute kidney injury after CABG versus PCI: an observational study using 2 cohorts. J Am Coll Cardiol. 2014;64:985-94.

24. Reddan D, Laville M, Garovic VD. Contrast-induced nephropathy and its prevention: what do we really know from evidence-based findings? J Nephrol. 2009:22:333-51.

25. Bagshaw SM, Culleton BF. Contrast-induced nephropathy: epidemiology and prevention. Minerva Cardioangiol. 2006;54:109-29.

Key Words: radiopaque coronary bypass marker, CABG, coronary angiography 